\title{
$1 \quad$ Field measurement of moisture-buffering model inputs for residential buildings
}

2 Jason Woods ${ }^{*}$ and Jon Winkler

3 National Renewable Energy Laboratory, 15013 Denver West Parkway, Golden, CO 80401 USA

$4 \quad *$ *orresponding author: Tel: 1-303-384-6189; email: jason.woods@nrel.gov

\begin{abstract}
Moisture adsorption and desorption in building materials impact indoor humidity. This effect should be included in building-energy simulations, particularly when humidity is being investigated or controlled. Several models can calculate this moisture-buffering effect, but accurate ones require model inputs that are not always known to the user of the building-energy simulation. This research developed an empirical method to extract whole-house model inputs for the effective moisture penetration depth (EMPD) model. The experimental approach was to subject the materials in the house to a square-wave relative-humidity profile, measure all of the moisture-transfer terms (e.g., infiltration, air-conditioner condensate), and calculate the only unmeasured term - the moisture sorption into the materials. We validated this method with laboratory measurements, which we used to measure the EMPD model inputs of two houses. After deriving these inputs, we measured the humidity of the same houses during tests with realistic latent and sensible loads and demonstrated the accuracy of this approach. These results show that the EMPD model, when given reasonable inputs, is an accurate moisture-buffering model.
\end{abstract}

Keywords: moisture capacitance; buildings; modeling; moisture buffering; effective penetration depth 


\section{INTRODUCTION}

2 Building-energy simulations can be used to predict a building's indoor conditions and determine the energy needed to keep these conditions comfortable. These models simulate the loads on the building (e.g., internal gains and envelope heat transfer), determine the operation of the space-conditioning equipment, and then calculate the building's temperature and humidity throughout the year. The indoor temperature and humidity are affected not only by the latent and sensible loads and the spaceconditioning equipment, but also, by the capacitance of the building materials that buffer changes in temperature and humidity.

For example, a sensible load changes the air temperature in an empty house with lightweight walls more quickly than in a furnished house with heavy walls, because much of the thermal energy is stored in the furnishings and the heavy walls rather than in the air. This can have a considerable effect on energy use, because the diurnal temperature variation can be buffered by this thermal capacitance. This capacitance is included in most building-energy models.

Similar to the thermal capacitance's effect on temperature, the moisture capacitance of a building's materials is important for predicting the indoor humidity. The materials adsorb ${ }^{1}$ or desorb moisture depending on changes in relative humidity $(\mathrm{RH})$ of the surrounding air. This moisture transfer buffers changes in humidity. Calculations of moisture storage and transport are often simplified or ignored in building-energy models. Even though the simplified models often adequately predict energy use, they do not adequately predict the indoor $\mathrm{RH}$, nor do they predict the correct energy use when humidity is controlled [1]. Predicting RH in homes has become important as envelope and lighting improvements have reduced the sensible load, while the latent load from internal gains and required ventilation has

\footnotetext{
${ }^{1}$ Moisture $a d$ sorption onto a material's surface (including its internal pore structure) and $a b$ sorption into the bulk material are collectively known as sorption. Both adsorption and absorption occur in building materials (adsorption at lower humidity, absorption at higher humidity). Adsorption is used in this paper to mean either type of sorption.
} 
remained relatively constant $[2,3]$. This can result in increased humidity and may require dehumidification equipment to maintain comfort and prevent moisture-related problems such as mold growth. Accurately predicting the indoor RH is essential to understanding these potential problems and to properly evaluating and selecting potential solutions.

The simplest method for including moisture capacitance in modeling is to increase the capacitance of the air in the building to account for the added capacitance of the materials. This effective capacitance (EC) model assumes that the volume of the air in the building is 10-15 times larger than the actual volume [46]. This model is not only unrealistic, but it also cannot be calibrated to give an accurate humidity response [1].

A complex method for studying moisture capacitance and moisture flows in building modeling is the finite-difference method, which spatially discretizes the differential equations within the material [7, 8]. This approach is accurate but requires long simulation times and several model inputs that are often unknown.

Another approach is the effective moisture penetration depth (EMPD) model [9-11]. This model assumes that the moisture is transferred between the zone air and a thin fictitious layer of material of uniform moisture content. The basis for this model is that the zone humidity is cyclical. If it is perfectly cyclical (e.g., a sine wave), then the model gives nearly the exact solution. If it is not perfectly cyclical, then it can still be a good approximation [12]. The EMPD model offers a more realistic approach than the EC model and a simpler approach than the finite-difference method.

The EMPD model requires inputs for the moisture properties (e.g., permeability, moisture sorption curve) and the surface areas for each material in the house. However, a single test can be used to measure these properties in aggregate, as several researchers have demonstrated [13-18]. Vereecken et al. [19] demonstrated an experimental method for simultaneously measuring a single set of EMPD model inputs for multiple materials. In this research, we extended that method to measure the moisture-buffering model inputs for a whole house in the field. 
The goal of this research was to measure and validate aggregate EMPD model inputs for use in a building-energy simulation. Three key elements were needed to achieve this goal:

1. The ability to measure moisture transfer into and out of materials in a house in the field.

Established methods for doing this, typically used in a laboratory, directly weigh the material as it adsorbs moisture; this is not feasible for a whole house.

2. A humidity profile that enables a fast, accurate, and reliable method for extracting the model inputs from measured moisture adsorption/desorption data.

3. Data that can validate the model and these extracted model inputs.

The research described in this paper addresses these three needs.

\section{TEST HOUSES}

Two unoccupied test houses were used in this research: a laboratory house at the Florida Solar Energy Center in Cocoa, Florida, and a production house in a neighborhood in Stockton, California.

House A: The first test house is one of two that comprise the Flexible Residential Test Facility [20], which was built in 2010. These houses are single-story, slab-on-grade construction with painted, uninsulated concrete block walls and R-19 attic insulation. The inside of the exterior walls has furring strips and painted drywall. The $143 \mathrm{~m}^{2}$ floor area is one large empty room. Furniture, carpet, and interior walls were added to the space. The interior walls consist of $16 "(40.6-\mathrm{cm})$ on-center $2 \times 4$ studs and two sheets of 12.5-mm drywall. They were not installed per a floor plan; rather, they were built in $2.4 \mathrm{~m} \times 1.2$ m sections and dispersed throughout the space to ensure a single zone with uniform conditions. Added furniture included three bedroom sets (with linens), kitchen table and chairs, and living room furniture. We covered all windows with $25 \mathrm{~mm}$ polyisocyanurate foam to eliminate the effects of solar gains and to ensure that no condensation formed on the single-pane windows. Exterior and interior photos of House A, including the moisture measurement equipment, are shown in Figures 1and 2. For more information and additional photographs of House A, see [20, 21]. 


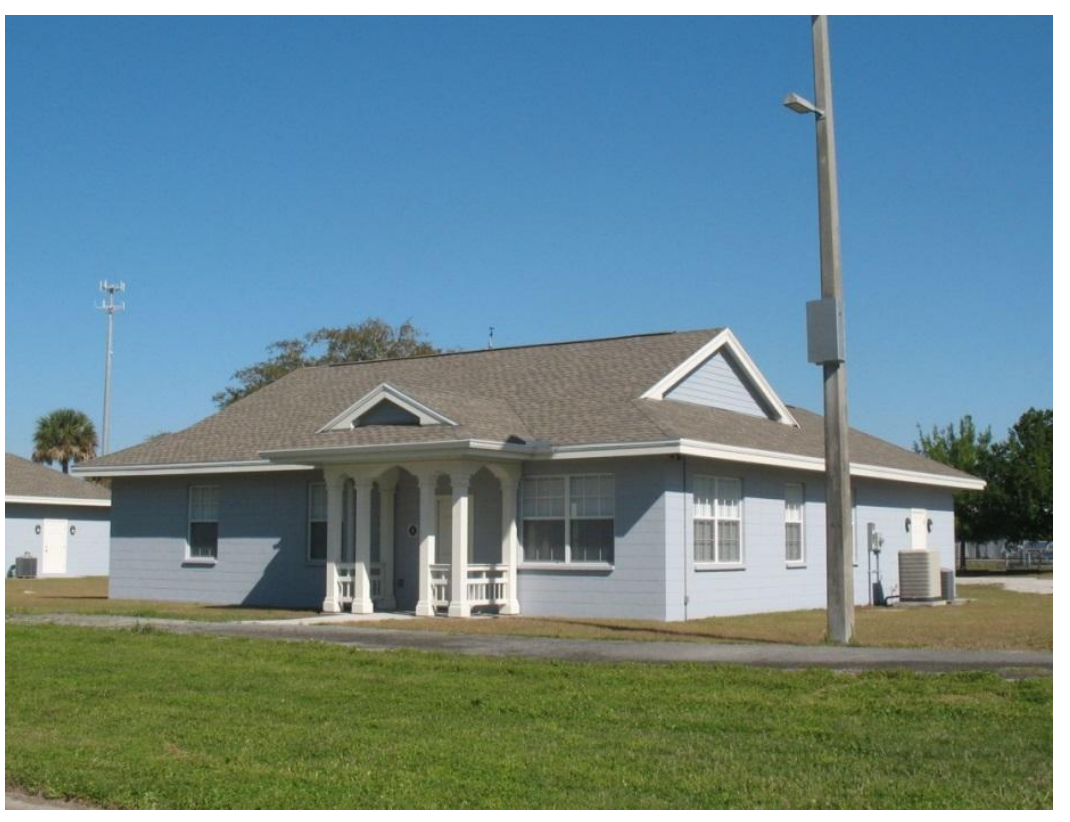

Figure 1: House A exterior.

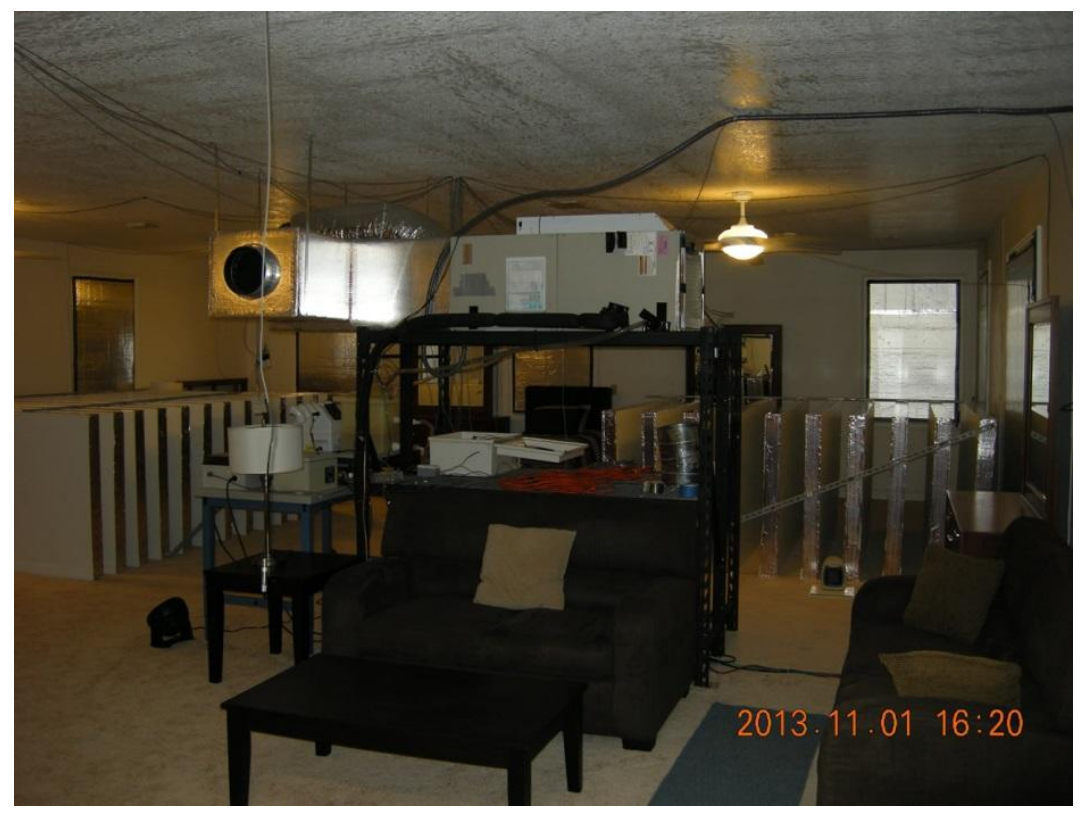

Figure 2: House A interior, showing furniture, carpet, interior wall sections and moisture measurement equipment (explained in Section 3.1.1). 
House B: The second house, in Stockton, California, was built in 2005 and is two stories. The exterior walls consist of 16" (40.6-cm) on-center, $2 \times 4$ studs with blown-in fiberglass insulation and $25 \mathrm{~mm}$ of exterior rigid expanded polystyrene insulation. The attic has R-30 of blown-in fiberglass. Furnishings for House B included the same as House A, plus office furniture, $19 \mathrm{~kg}$ of clothing and linens, and $30 \mathrm{~kg}$ of paper and cardboard. Exterior and interior photos of House B are shown in Figures 3 and 4, including both (a) upstairs (where the moisture measurement equipment was installed), and (b) downstairs. For more information and additional photographs of House B, see "Caleb" house in [22].

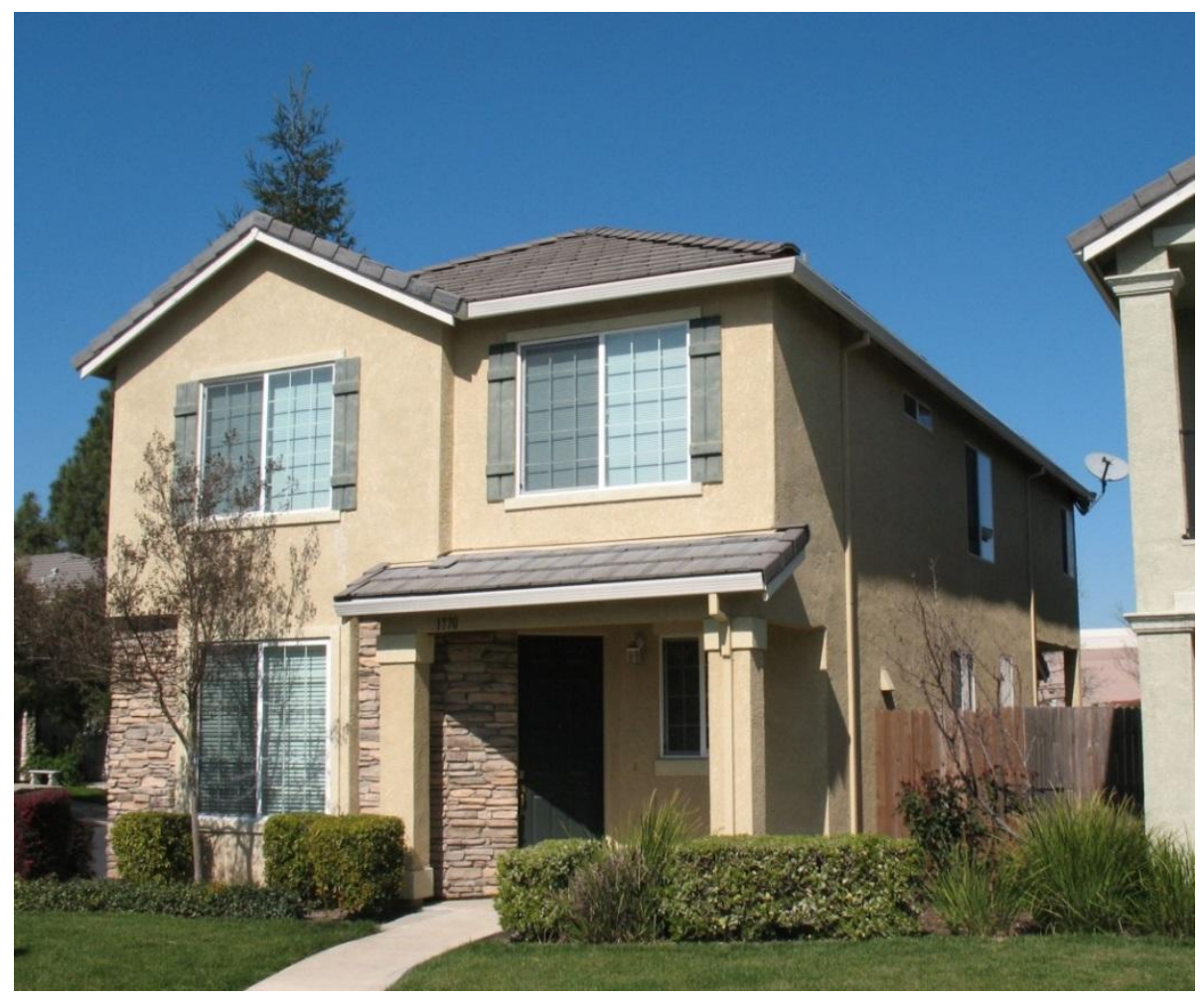

Figure 3: House B exterior. 


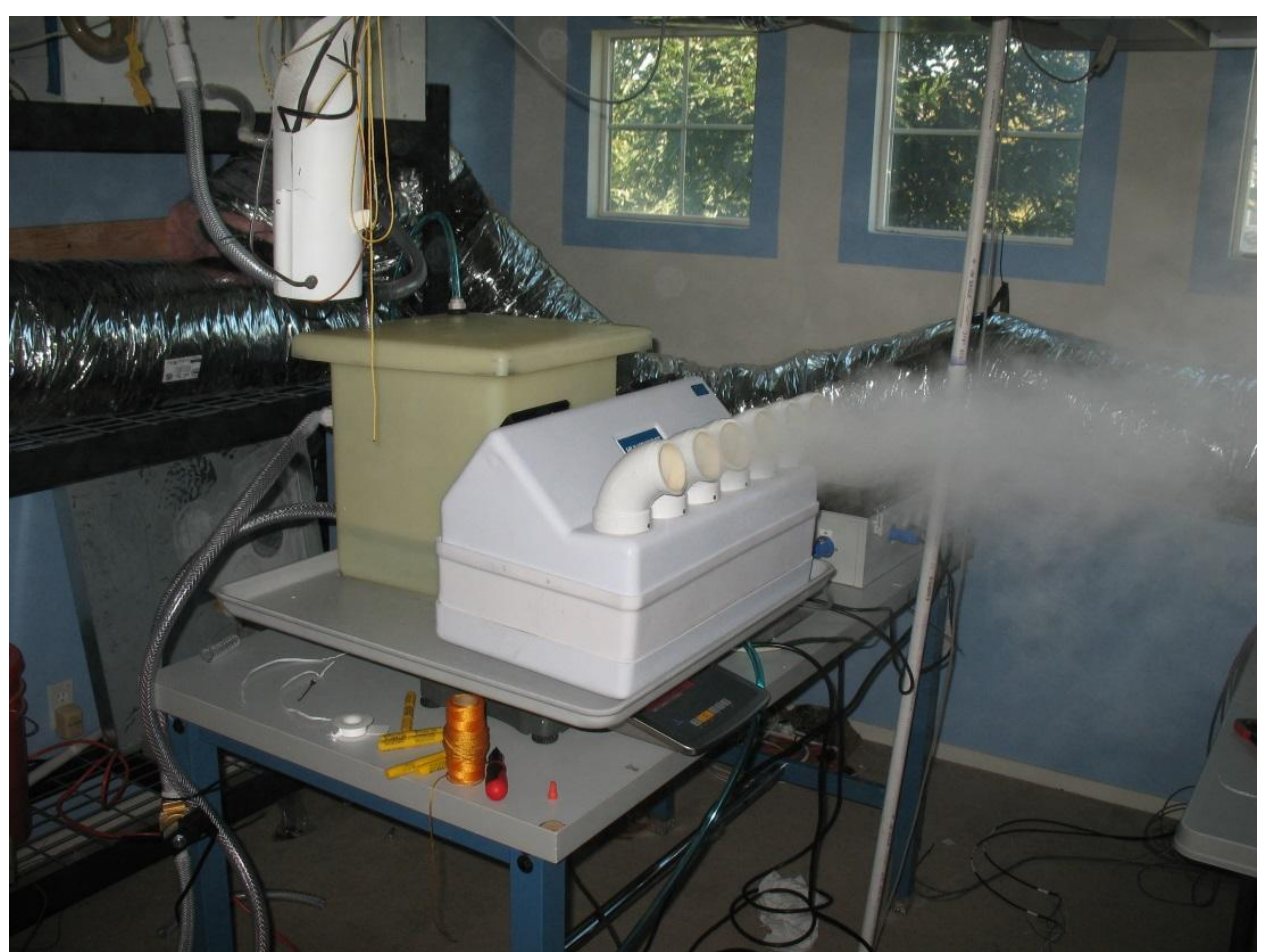

(a)

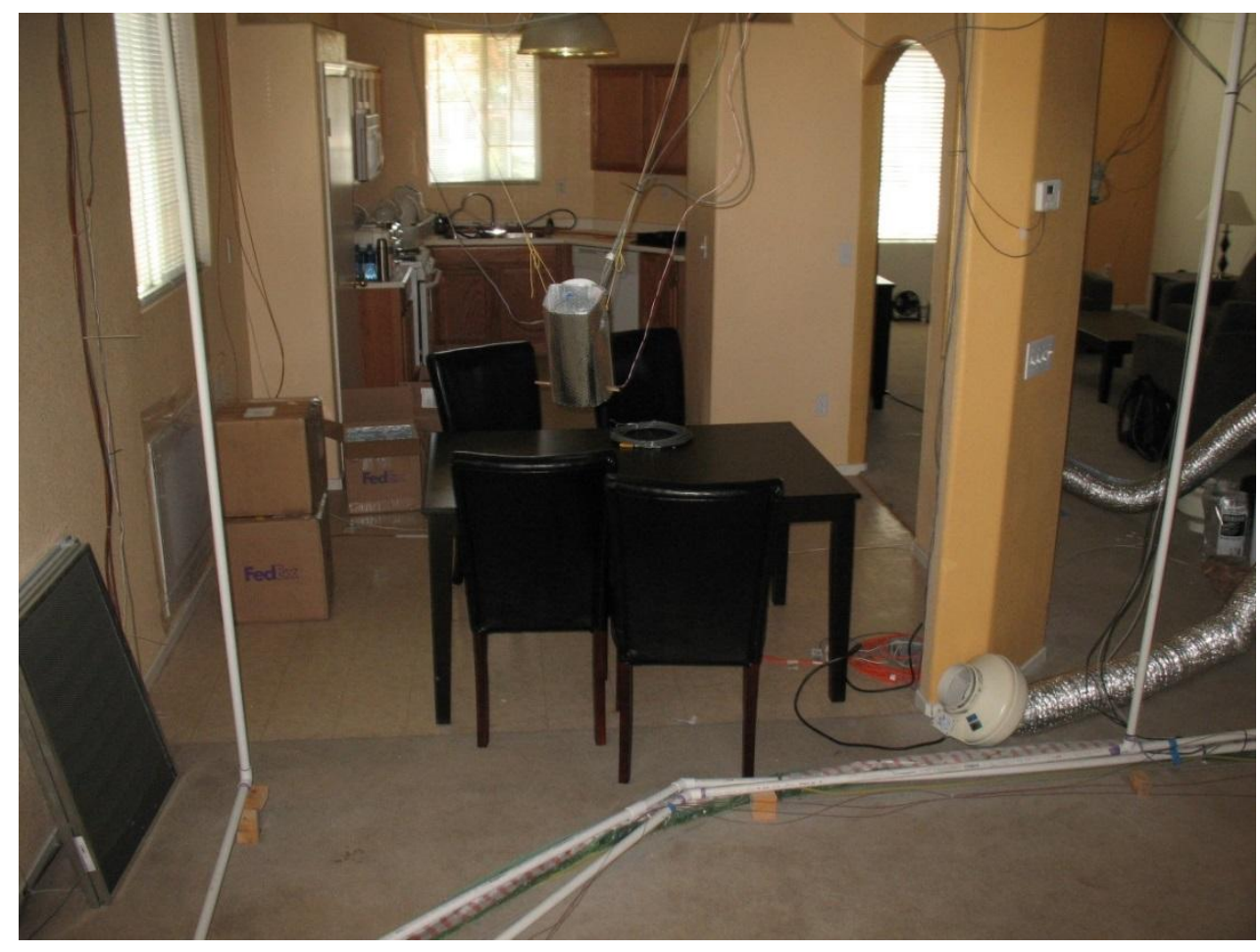

(b)

Figure 4: House B interior, (a) upstairs with moisture measurement equipment (described in Section 3.1.1), (b) downstairs. 


\section{Methods}

2 The following subsections describe the methods that were used to address the three key needs: (1) a

3 method for measuring material moisture adsorption in the field, (2) a method for extracting EMPD model

4 inputs, and (3) a data set to validate this extraction method.

\subsection{Measuring material moisture adsorption in the field} single zone):

$$
\rho_{\text {air }} V_{z o n e} \frac{d \omega_{\text {zone }}}{d t}=\dot{m}_{v, \text { inf }}+\dot{m}_{v, \text { gain }}-\dot{m}_{v, H V A C}-\dot{m}_{v, \text { matl }}
$$

where $\rho_{\text {air }}$ is the air density, $V_{\text {zone }}$ is the zone volume, and $\omega_{\text {zone }}$ is the zone humidity ratio. Each term on the right-hand side is a moisture exchange with the zone: $\dot{m}_{v}$ inf is the moisture entering the zone through

$$
M_{v, \text { matl }}=M_{v, \text { inf }}+M_{v, \text { gain }}-M_{v, \text { HVAC }}-M_{v, \text { air }}
$$

where $M_{v, \text { matl }}$ is defined as:

$$
M_{v, \text { matl }}=\int_{0}^{t} \dot{m}_{v, \text { matl }}(t) d t
$$




\subsubsection{Moisture-transfer measurements}

\begin{tabular}{ll}
\hline Measurement & Measurement method and instrumentation \\
\hline $\begin{array}{l}\text { Moisture addition/removal } \\
\left(M_{v, \text { gain }}-M_{v, H V A C}\right)\end{array}$ & Sartorius Signum 35-kg scale $( \pm 0.001 \mathrm{~kg})$ \\
Zone air humidity $\left(M_{v, \text { air }}\right)$ & Vaisala HMP-110 T\&RH sensor $\left( \pm 0.2{ }^{\circ} \mathrm{C} ; \mathrm{RH}: \pm 1.7 \%\right)$ \\
Infiltration $\left(M_{v, \text {, in }}\right) ;$ House A & $\begin{array}{l}\text { Continuous } \mathrm{CO}_{2} \text { tracer gas (Dakota mass flow meter }( \pm 0.075 \mathrm{~L} / \mathrm{min}) \text { and GE } \\
\text { Ventostat } \mathrm{CO}_{2} \text { concentration transmitters }( \pm 3 \%)\end{array}$ \\
Infiltration $\left(M_{v, \text {, in }}\right) ;$ House B & $\begin{array}{l}\text { SF6 tracer gas test, with data fit to Eq. }(7) . \text { Bruel and Kjaer } 1302 \\
\text { Photoacoustic Gas Analyzer. }\end{array}$ \\
\hline
\end{tabular}

The terms on the right-hand side of Eq. (2) are measured as described below. Table 1 lists each measurement and the corresponding instruments.

Table 1: Key measurements and instrumentation for terms in Eq. (2)
5

Moisture addition/removal: We used an ultrasonic humidifier (Humidifirst MP-15) and dehumidifier (Ultra-aire XT155H) to control the humidity in the zone. The humidifier draws water from a tank; we collected the dehumidifier and air-conditioner condensate flows in this same tank. In both houses, the air conditioner and all its ducts are located within conditioned space.

We then measured the cumulative moisture addition $\left(\mathrm{M}_{\mathrm{v}, \mathrm{gain}}-\mathrm{M}_{\mathrm{v}, \mathrm{HVAC}}\right)$ by weighing this tank of water with a scale (Figure 5):

$$
M_{v, \text { gain }}(t)-M_{v, H V A C}(t)=M_{\text {scale }}(0)-M_{\text {scale }}(t)
$$

This cumulative measurement gives much lower uncertainty than continuously measuring water flow rates. 


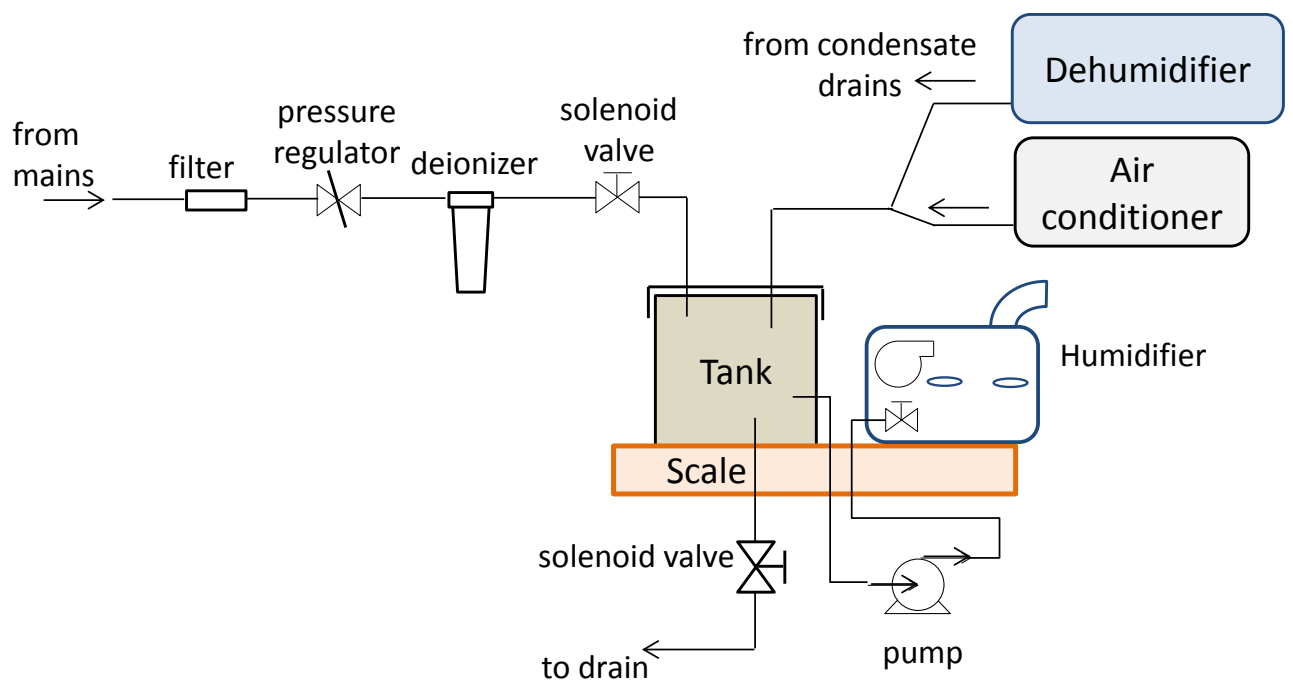

Figure 5: Experimental setup for adding and removing moisture

Zone air humidity: The zone air humidity is the average of multiple T\&RH sensor measurements in each house. These sensors were checked against an accurately calibrated dew-point hygrometer and thermocouple at the National Renewable Energy Laboratory's Advanced HVAC Systems Laboratory [23]. With these humidity measurements, we calculated the cumulative moisture transferred to the zone air up until time $t$ :

$$
M_{v, \text { air }}=\rho_{\text {air }} V_{\text {zone }}\left[\omega_{\text {zone }}(t)-\omega_{\text {zone }}(0)\right]
$$

In House A, which is one large room, four T\&RH sensors are equally spaced and $1.2 \mathrm{~m}$ from the floor.

0 House B has eight T\&RH sensors dispersed throughout, primarily at the center of each room. The

1 temperature of the zone air is controlled by the air conditioner and by $1.5-\mathrm{kW}$ electric resistance heaters

2 that are controlled independently by the local temperature. In House B, we used several ducted fans to mix the air, primarily between the first and second floors.

Infiltration: Calculating moisture addition or removal from infiltration requires the air infiltration rate and the indoor and outdoor humidity ratios: 
$1 \quad M_{v, \text { inf }}=\int_{0}^{t} \dot{m}_{\text {air,inf }}(t)\left[\omega_{\text {amb }}(t)-\omega_{\text {zone }}(t)\right] d t$

2 We measured the air infiltration rate in different ways for houses A and B. House A used a constant-

3 injection tracer-gas test with $\mathrm{CO}_{2}$, a capability that already existed in this house [21,24]. This allowed us

4 to continuously measure the infiltration. House B used several decay tracer-gas tests with $\mathrm{SF}_{6}[21,25]$,

5 and these data were used to fit an infiltration model [26] as a function of the difference between indoor

6 and outdoor temperatures and the wind speed:

$7 \quad \dot{m}_{\text {air }, \text { inf }}=\sqrt{\left(0.0063 \Delta T_{\text {in-out }}^{0.35}\right)^{2}+\left(0.0047 V_{\text {wind }}^{0.7}\right)^{2}}$

An anemometer measured wind speed at the house site. Uncertainties in both methods were found to have only a minor effect on the measurement of the moisture-buffering model inputs, especially in the relatively tight houses used in this research.

\subsubsection{Verifying moisture-transfer measurements}

We used a two-step process to verify the accuracy of these measurements [21]: we linked our new measurement method, which uses Eq. (2), to an established method in which the moisture transfer is measured by weighing the sample that adsorbed moisture (e.g., see [27]). We used both methods simultaneously in a well-controlled laboratory chamber, which showed that the new method agrees with the material weighing method within $2 \%$. We then performed a test on the same material in House A, which gave consistent results (within 4\%) to those in the laboratory. These results link the established method in the laboratory to the new method in the field. This enables the new method to be used for more complex testing in the field, including calculating whole-house moisture-buffering model inputs, as described below. Details about these tests are included in [21]. 


\subsection{Extracting moisture-buffering model inputs}

To extract the EMPD model parameters from field data, we started with the equations of the EMPD model. The full set of equations appears elsewhere [21]. Here, we briefly summarize the model and review the equations needed for the model-input extraction method.

The model can be visualized with Figure 6 . The material-air coupling occurs through a resistance $\left(1 / k_{\text {sur }}\right)$ between the zone air and a surface layer, which is a fictitious layer with an assumed uniform moisture content. This surface layer is also connected to a deep layer through a second resistance $\left(1 / k_{\text {deep }}\right)$. The surface layer responds relatively quickly to changes in humidity and damps higher-frequency changes in the zone humidity (e.g., daily fluctuations from daytime air-conditioner use). The deep layer typically has a higher capacitance for moisture storage, but responds more slowly. It damps lower-frequency changes in the zone humidity (e.g., changes due to weather patterns). This model provides nearly the exact solution when the humidity load is from two superimposed load profiles with constant frequencies [12].

\section{moisture sorbent material}

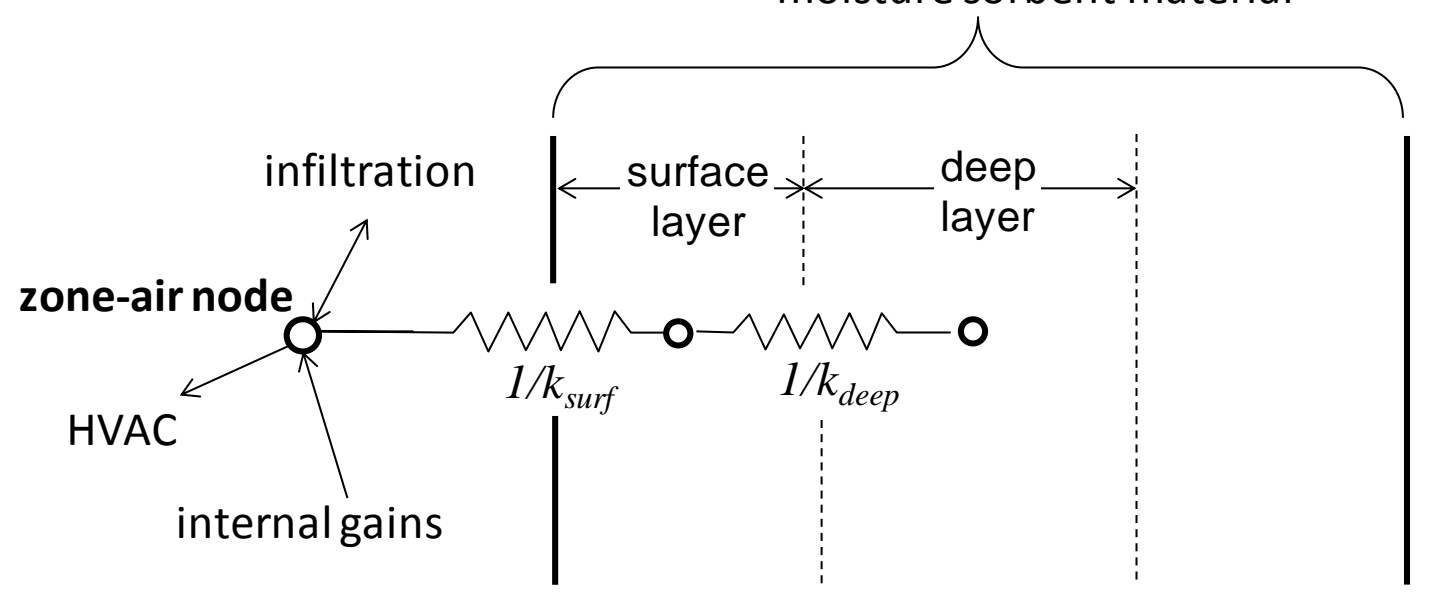

Figure 6: Schematic of EMPD model

The key equations are from moisture balances on the surface and deep layers:

$A d_{E M P D-\text { surf }} \frac{d w_{\text {surf }}(t)}{d t}=k_{\text {surf }} A\left[w_{\text {zone }}(t)-w_{\text {surf }}(t)\right]$ 
$1 \quad A d_{E M P D-\text { deep }} \frac{d w_{\text {deep }}(t)}{d t}=k_{\text {deep }} A\left[w_{\text {surf }}(t)-w_{\text {deep }}(t)\right]$

In these equations, $k_{\text {surf }}, w_{\text {surf }}$, and $d_{E M P D-\text { surf }}$ are the mass transfer coefficient, moisture content, and effective moisture penetration depth for the surface layer, and $k_{\text {deep }}, w_{\text {deep }}$, and $d_{E M P D \text {-deep }}$ are the corresponding values for the deep layer. The total surface area of the material $(A)$ is assumed to be the same for both layers. The zone humidity ratio $\left(\omega_{z o n e}\right)$ is converted to an equivalent material moisture content $\left(w_{\text {zone }}\right)$ through the material's moisture sorption curve:

$$
w_{\text {zone }}=\frac{d w}{d \phi} \frac{P \omega_{\text {zone }}}{p_{\text {sat }}\left(0.622+\omega_{\text {zone }}\right)}
$$

where $d w / d \phi$ is the slope of the moisture sorption curve (assumed constant with no hysteresis), $P$ is the absolute pressure, and $p_{\text {sat }}$ is the saturated vapor pressure at the zone temperature. The mass transfer coefficients in Eqs. (8) and (9) are defined as [21]:

$$
k_{\text {surf }}=\frac{2 \delta_{p} p_{\text {sat }}}{d w / d \phi d_{E M P D-s u r f}}
$$

$$
k_{\text {deep }}=\frac{1}{\frac{1}{k_{\text {surf }}}+\frac{d w / d \phi d_{E M P D-\text { deep }}}{2 \delta_{p} p_{\text {sat }}}}
$$

where $\delta_{p}$ is the vapor permeability of the material. We did not include the air-side boundary layer coefficient in Eq. (11); this had a negligible effect on the results, because this boundary layer resistance is orders-of-magnitude lower than the material diffusive resistance for common building materials.

From Eqs. (8-9) and (11-12), we see that the model inputs for the moisture-adsorbent material(s) in the EMPD model are:

1. Surface area, $A\left(\mathrm{~m}^{2}\right)$

2. Moisture-sorption curve slope, $d w / d \phi\left(\mathrm{kg} \mathrm{m}^{-3} \mathrm{RH}^{-1}\right)$ 
3. Moisture permeability, $\delta_{p}\left(\mathrm{~kg} \mathrm{~m}^{-1} \mathrm{~s}^{-1} \mathrm{~Pa}^{-1}\right)$

4. Surface-layer penetration depth, $d_{E M P D-s u r f}(\mathrm{~m})$

5. Deep-layer penetration depth, $d_{E M P D-d e e p}(\mathrm{~m})$

As discussed in our previous report, some of these inputs show up in the same term, and only three independent parameter groupings fully define the EMPD model [21]. We can assume values for the material properties (inputs 2 and 3 ) and use the measured data to extract values for the other three inputs. We do not intend to find the actual surface areas or thicknesses of the moisture-sorbent materials in the house. Rather, we want representative values that match the data.

The goal of this research was to use field tests on houses A and B to extract these three values. This required a humidity forcing function that provided fast, repeatable, and accurate results. Our approach was to oscillate the house between high (65\%) and low (35\%) relative humidity (Figure 7), repeating the pattern as a square wave using two periods: 24 hours and 2 weeks. The temperature was held constant during these square-wave profiles.

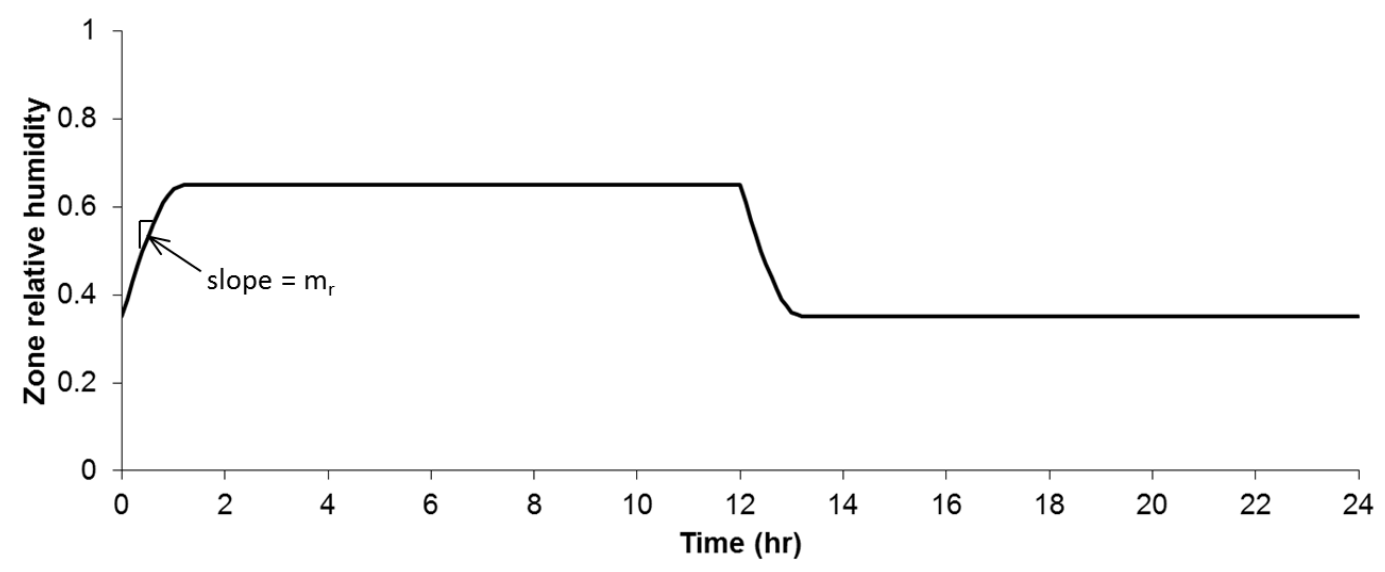

(a) 


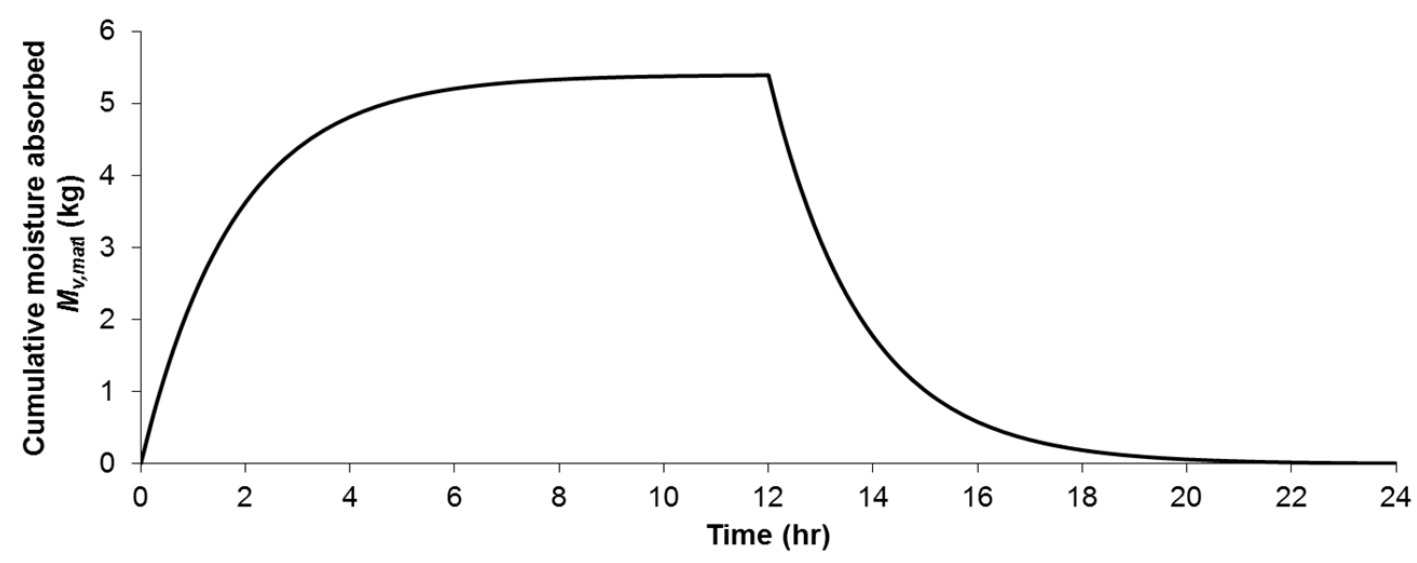

(b)

Figure 7: Illustrative example of square-wave test profile: (a) RH input, and (b) resulting cumulative moisture adsorption

This step-change profile enables an exact solution to Eqs. (8) and (9), the derivation of which is detailed

in [21]. The equations are for the total accumulated moisture in the material. We developed two equations

for the 24-hour test: one for the initial ramp in $\mathrm{RH}$ (with slope $m_{r}$ ), because the profile is not a perfect

square wave, and one for the steady-state period following the ramp (the ramp is assumed to end, and the steady-state period begin, at time $\left.t_{1}\right)$ :

$M_{v, \text { surf }}(t)=A d_{E M P D-\text { surf }} \frac{d w}{d \phi} m_{r}\left(t-\frac{d_{E M P D-\text { surf }}}{k}\left[1-\exp \left(\frac{-k_{\text {surf }}}{d_{E M P D-\text { surf }}} t\right)\right]\right) \quad 0<t \leq t_{1}$

$$
M_{v, \text { surf }}(t)=M_{v, \text { surf }}\left(t_{1}\right)+A d_{E M P D-\text { surf }}\left(\frac{d w}{d \phi} \phi_{\text {zone }, f}-w_{\text {surf }}\left(t_{1}\right)\right)\left[1-\exp \left(\frac{-k_{\text {surf }}}{d_{E M P D-\text { surf }}}\left(t-t_{1}\right)\right)\right] t>t_{1}
$$

For the 2-week test, the ramp period is unimportant, and the total accumulated moisture in both layers is:

$3 M_{v, \text { total }}(t)=M_{v, \text { surf }}(t)+A d_{E M P D-\text { deep }} \frac{d w}{d \phi}\left(\phi_{\text {zone, },}-\phi_{\text {zone }, i}\left[1-\exp \left(\frac{-k_{\text {deep }}}{d_{\text {EMPD-deep }}} t\right)\right] \quad t>0\right.$ 
We compared the data from several 24-hour tests to Eqs. (13) and (14) and from the 2-week tests to Eq. (15). We found the three model inputs by minimizing the sum of the square of the errors between the data and the model.

\subsection{Validating the model inputs}

The third need is for a test with a realistic indoor humidity profile that includes enough variation to validate the data-extraction method. The heaters and humidifier simulated occupants and internal gains, and the heaters and air conditioner controlled the zone temperature. The dehumidifier was turned off. We performed this validation test in both houses.

In House A, the set points were constant $\left(21.1^{\circ} \mathrm{C}\right.$ heating, $25^{\circ} \mathrm{C}$ cooling $)$. The weather during these tests (December in Florida) offered enough variation to assess our extraction method. The internal-gain profile was the same each day and was based on the Building America House Simulation Protocols [28]. We also added internal gains that mimicked solar gains through windows, because the windows were covered. These were calculated assuming a relatively clear day and a solar heat gain coefficient of 0.3 .

The weather at House B (May in Stockton, California) was roughly the same from one day to the next, but we used five distinct internal-gain profiles to give the required variation to assess the accuracy of our extraction method. The sensible gain averaged $16 \mathrm{kWh} /$ day and the latent gain averaged $7.2 \mathrm{~kg} / \mathrm{day}(5$ kWh/day). However, these gains varied significantly, including a high-load day with a 31-kWh sensible load and a 14-kg latent load and a day with no internal latent generation. The temperature set points were $24{ }^{\circ} \mathrm{C}$ for cooling and $22.5^{\circ} \mathrm{C}$ for heating; they also included two 2-day periods during which the thermostat was off to simulate time when the occupants were away from home.

To isolate the moisture-buffering model, we simplified the sensible energy calculations by setting the zone temperature in the model equal to the measured value at each time step. This eliminated any uncertainty with the heat transfer model, which was not evaluated. We did, though, need to calculate the moisture removal by the air conditioner, because this impacts the moisture balance. We correlated the 
modeled moisture-removal capacity of the air conditioner to the measured removal as a function of RH and calculated the latent removal at each time step. We prefer this approach over using the measured latent removal directly, because the modeled latent removal is a function of the zone humidity, and the modeled zone humidity does not, in general, match the measured zone humidity at each time step.

Other inputs into the model include the ambient humidity (used to calculate the latent infiltration exchange), barometric pressure (used to calculate various psychrometric functions), and zone volume.

\section{RESUltS AND DiscuSSION}

This section is divided in two. We first present results for the parameter-extraction method: the model inputs that were extracted based on the square-wave humidity profiles. We then present results for the simulated occupancy tests and compare the measured humidity with humidity predicted by the EMPD model that used these extracted model inputs.

\subsection{Parameter extraction}

Figure 8 shows the measured cumulative moisture adsorption for the 24-hour tests for House A (open circles) and House B (open squares). The adsorbed moisture during the first 12 hours typically differed from the desorbed moisture during the second 12 hours by less than $5 \%$. The curve in Figure 8 was adjusted so that the total moisture adsorbed and desorbed was the same. The least-squares fits to the data, using Eqs. (13) and (14), are shown with the solid and dashed lines for House A and House B, respectively. These were obtained by adjusting the total surface area and the surface-layer penetration depth model inputs. The final independent model input was obtained by fitting Eq. (15) to the 2-week test data, which are shown in Figure 9.

Uncertainty was higher for the early parts of the test, but the derived parameters were not sensitive to this uncertainty, as discussed in the detailed uncertainty analysis in our previous report [21]. 


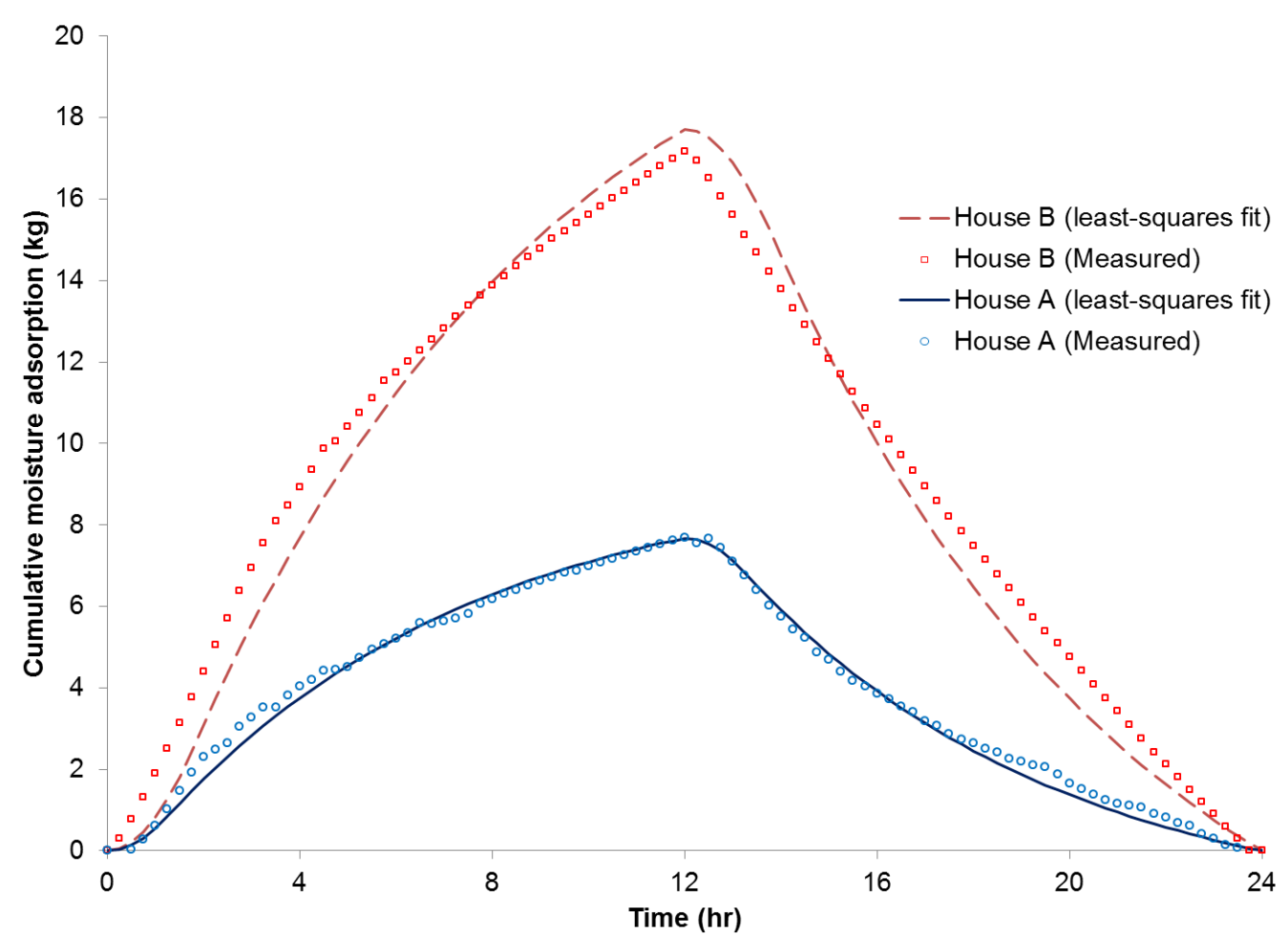

Figure 8: Empirical fit of Eqs. (13) and (14) to 24-hour test data

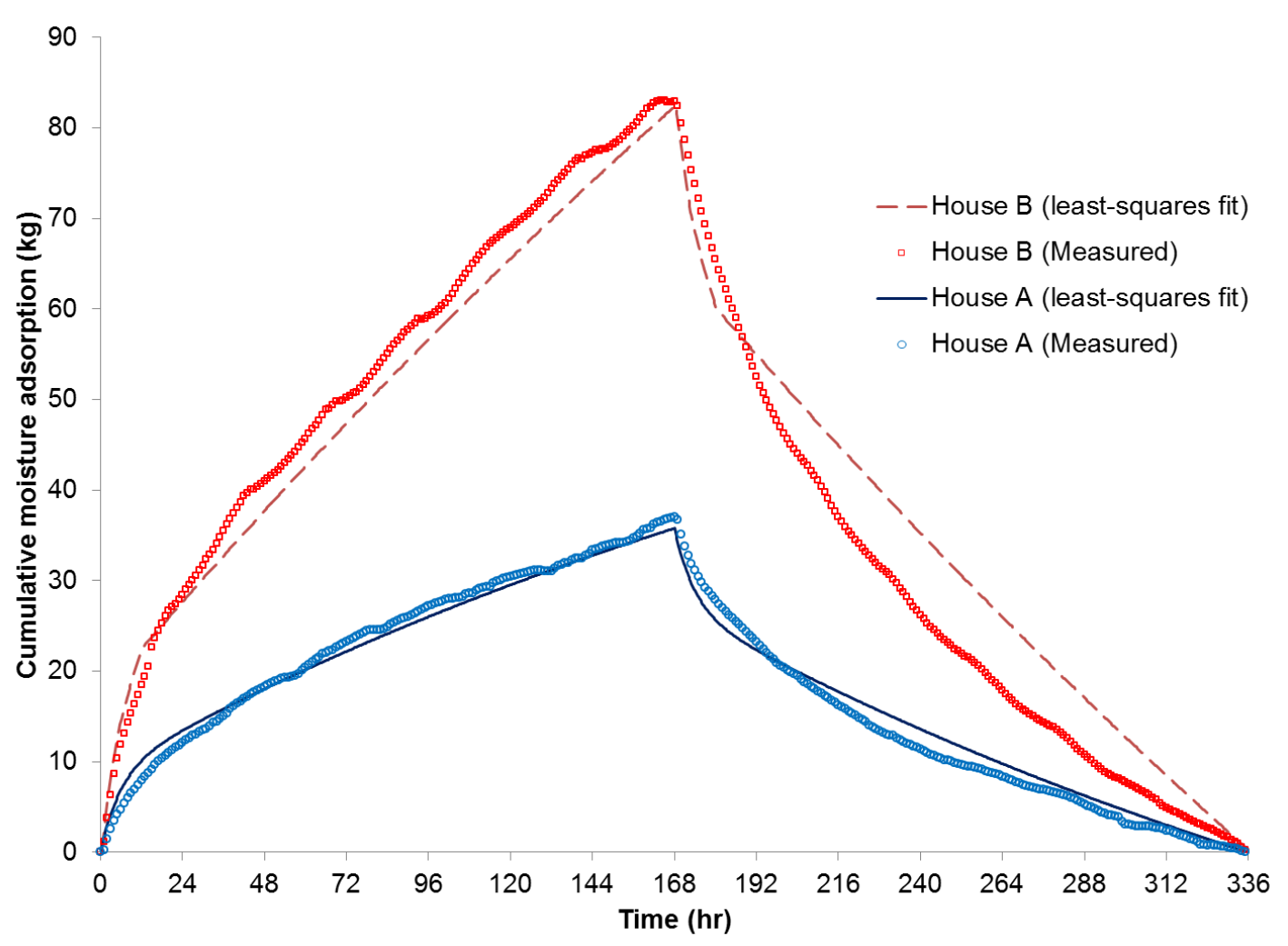


The best-fit parameters for the lines in Figures 8 and 9 are shown in Table 2. Because there are only three independent inputs, we assumed values for the two material properties to get more intuitive inputs. This means that the surface area is not, in general, the actual surface area of moisture-sorbent materials in the home. Instead, the five inputs are an effective set of model inputs that fit the measured data.

Two key takeaways emerged from these results:

1. The penetration depths for the surface and deep layers are similar in both houses. This implies that these parameters are independent of the amount of moisture-sorbent materials; rather, they are a function of the type of moisture-sorbent materials present.

2. The results indicate that House B had a much greater moisture-buffering effect than House A. This is as expected, because House B is larger (36\% more floor area), has more construction materials per square foot (same as House A + doors, trim, stairs, railings, shelves, built-in cabinets, fiberglass insulation), and had more furnishings (same as House A + clothing and linens, paper, cardboard).

These two houses could be thought of as representing a minimally furnished house and an average furnished house. In building energy simulations, which may be used to evaluate a certain technology in a range of climates, a specific house with known furnishings may not be available. Instead, we often want a representative amount of moisture-sorbent material for a typical house. Future research will focus on determining this representative amount based on these field test data.

Table 2: Extracted model inputs, assuming $\delta_{\mathrm{p}}=2.5 \times 10^{-11} \mathrm{~kg} / \mathrm{m}-\mathrm{s}-\mathrm{Pa}$ and $\mathrm{dw} / \mathrm{d} \phi=10 \mathrm{~kg} / \mathrm{m}^{3}-\mathrm{RH}$

\begin{tabular}{lrr}
\hline & House A & House B \\
& & \\
\hline Surface area, $\mathrm{A}\left(\mathrm{m}^{2}\right)$ & $162 \pm 8$ & $504 \pm 20$ \\
Surface-layer depth, $\mathrm{d}_{\mathrm{EMPD}-\text { surf }}(\mathrm{m})$ & $0.019 \pm 0.0007$ & $0.020 \pm 0.0007$
\end{tabular}




$$
\text { Deep-layer depth, } d_{\text {EMPD-deep }}(m) \quad 0.113 \pm 0.016 \quad 0.176 \pm 0.022
$$

\subsection{Simulated occupancy tests}

With the extracted model inputs, we can calculate the moisture-buffering term in Eq. (1) and predict the indoor humidity. The simulated occupancy tests provide measured data to compare to this predicted humidity. Figures 10 and 11 compare the modeled and measured indoor RH for House A and House B, respectively. We calculated the coefficient of variation of the root-mean square error to compare the relative improvement of the EMPD model over the commonly used EC model. This is calculated with:

$\mathrm{CV}(\mathrm{RMSE})=\frac{\sqrt{\sum_{i=1}^{N}\left(\phi_{\text {meas }}-\phi_{\text {model }}\right)^{2} / N}}{\phi_{\text {meas avg }}}$

where $\phi_{\text {meas }}$ is the measured $\mathrm{RH}$ at a given time, $\phi_{\text {model }}$ is the modeled $\mathrm{RH}$ at that same time, $\phi_{\text {meas,avg }}$ is the average of all RH measurements, and $N$ is the number of measurements. The CV(RMSE) values in the figures, which quantify the deviation of the model from the measurements, show the improvement of the EMPD model's prediction ability over the EC model.

Note that the EC model, with its single model input, cannot be adjusted to match the model any better than the CV(RMSE) shown in the figures. This EC value was adjusted after the simulated occupancy tests; we found the near-optimal value by plotting $\mathrm{CV}(\mathrm{RMSE})$ versus $\mathrm{EC}$ for a range of EC values. It is relatively sensitive to this value; using a typical value of $\mathrm{EC}=15$, the $\mathrm{CV}(\mathrm{RMSE})$ values increase to 0.115 for House A and to 0.112 for House B. Common EC values from the literature range from 10 to 25 $[3,5,6,29]$. 

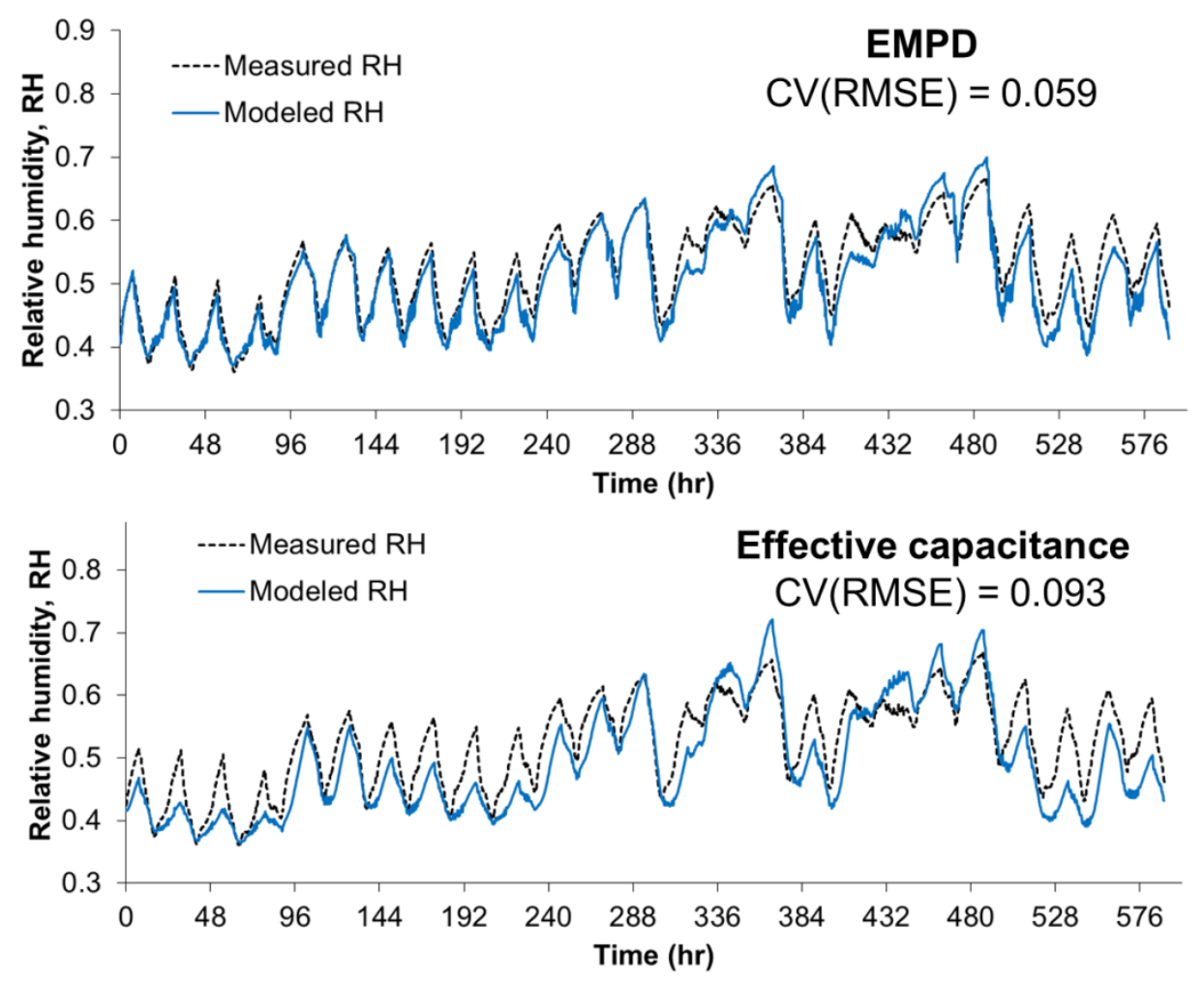

2 Figure 10: Comparison of EMPD and effective capacitance $(\mathrm{EC}=5)$ models to measured RH for House

A. 

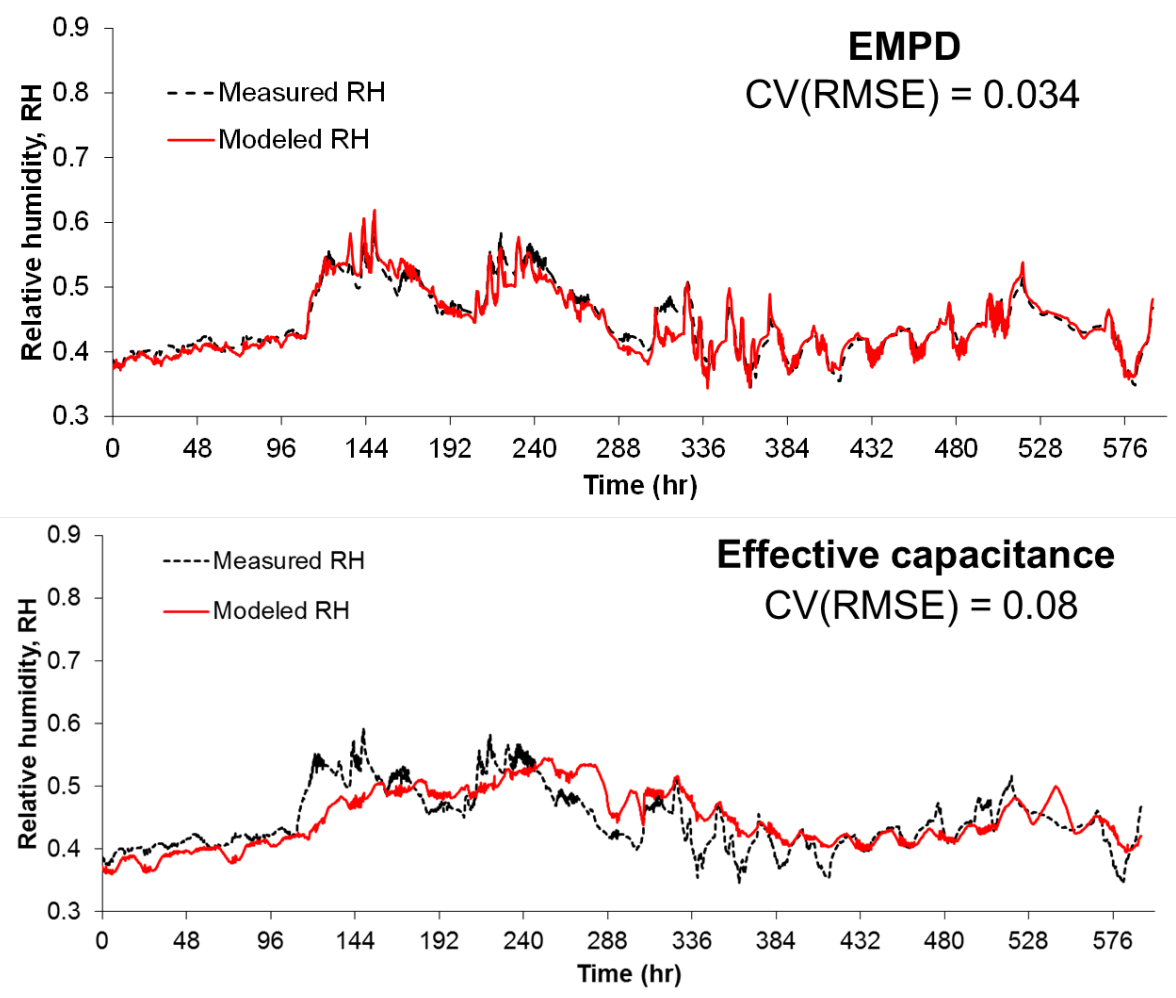

Figure 11: Comparison of EMPD and effective capacitance $(E C=30)$ model to measured RH for House

B.

4 A simple sensitivity analysis indicates the importance of measuring these parameters. We used the

5 measured parameters for House A in a simulation of House B. We first adjusted the area input to be on a

6 square foot basis but left the other parameters the same (theoretically, the penetration depth does not

7 depend on the house size). These results are shown in Figure 12, which shows the sensitivity to various

8 levels of furnishings. In our previous report, we presented a detailed uncertainty analysis. We found that

9 the results are insensitive to measurement uncertainty, and, in fact, the uncertainty could be much higher without much loss in accuracy. However, as illustrated with this case, a $2 \mathrm{X}$ difference in the surface area model input $(A)$ leads to unacceptable results. 


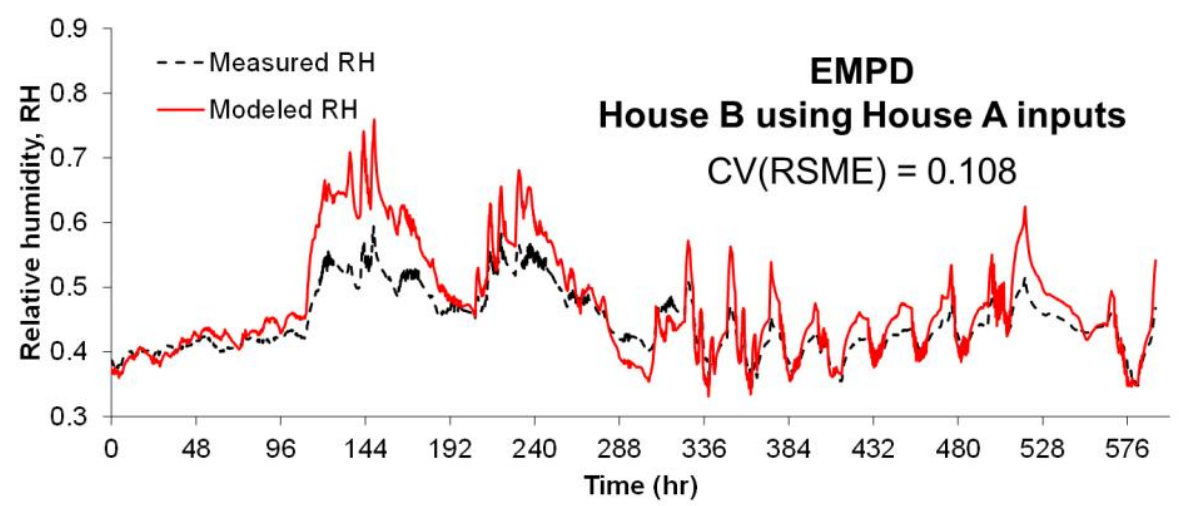

2 Figure 12: Comparison of EMPD model to measured RH for House B when using House A model inputs

\section{CONCLUSIONS}

A new method was used to extract moisture-buffering model inputs for building energy simulations by measuring all other moisture flows. This method was validated by linking an established measurement method in the laboratory to this new method in the field. The method was used to derive model inputs for two houses. We then used simulated latent and sensible gain profiles to validate this approach against the data. This validation also increases confidence in the EMPD model.

The following conclusions can be drawn from this research:

1. Confirming a conclusion from [21] for House A, the tests on House B show that the results are insensitive to measurement uncertainty for the cumulative measurement approach used here.

2. Indoor RH can be accurately predicted without including the moisture-content dependency of the material properties (e.g., moisture-dependent permeability, non-constant slope of moisture sorption curve).

3. Although this two-layer EMPD model was derived based on the superposition of only two cyclical humidity profiles, and the extraction method used only two test periods ( 24 hours and 2 weeks), the EMPD model can accurately predict indoor RH for humidity profiles with significant randomness, whether it is from internal gains (House B) or from the weather 
(House A). This research did not measure the level of randomness that leads to unacceptable inaccuracy.

4. Model results are sensitive to actual differences in moisture-buffering levels, as demonstrated by the amount of buffering from House B versus House A. Thus, some understanding of the home and its furnishings is required to accurately predict a home's indoor RH.

One limitation of this research is that it does not consider moisture transfer across the envelope. The data, which showed that the adsorbed moisture matched the desorbed moisture within 5\%, indicate that this envelope moisture transfer was small compared to the other moisture sources and the moisture buffering for these two houses. However, this result cannot be generalized to all home constructions. For example, a home may have moisture sources from a basement or crawlspace foundation, or moisture transfer across the walls could be significantly higher for a wood-frame home without rigid exterior insulation. This envelope moisture transfer can be calculated independently of the transfer into and out of the materials discussed in this paper.

Future research will focus on using these results, along with other field data and material properties, to develop a simplified correlation for the EMPD model inputs based on typical house properties such as square footage, location, or vintage.

\section{LIST OF SYMBOLS}

A surface area of moisture-sorbent material $\left(\mathrm{m}^{2}\right)$

$\mathrm{CV}$ (RSME) coefficient of variation of the root-mean-square error

$d_{E M P D} \quad$ effective moisture penetration depth (m)

$k \quad$ mass transfer coefficient $\left(\mathrm{m} \mathrm{s}^{-1}\right)$

$$
\mathrm{M}_{\text {scale }} \quad \text { scale reading }(\mathrm{kg})
$$

$\mathrm{M}_{\mathrm{v}} \quad$ cumulative moisture transfer $(\mathrm{kg})$ 


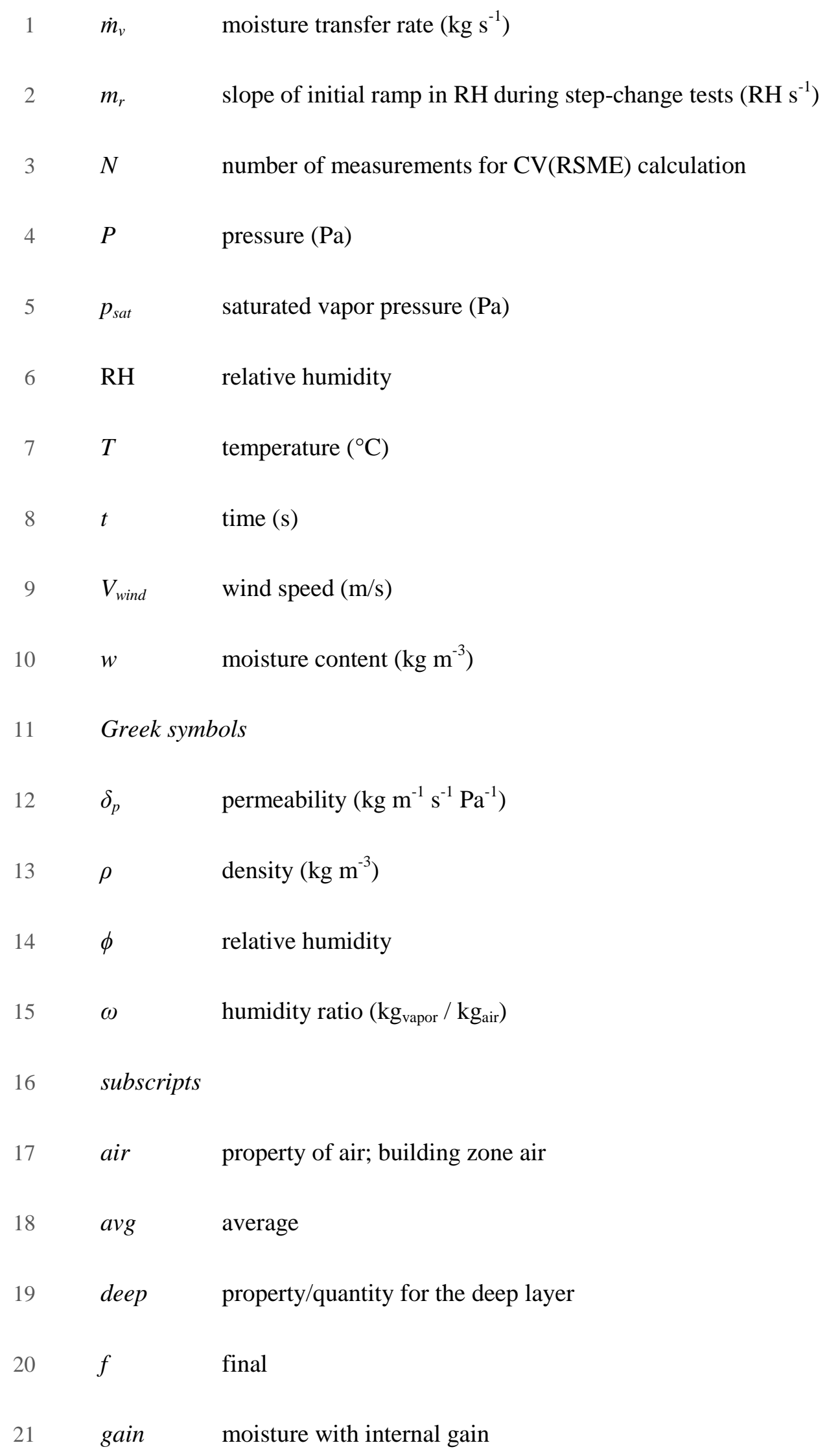


HVAC moisture removed with heating or air conditioning equipment

$$
\text { inf infiltration }
$$

matl

moisture associated with moisture-sorbent material

4

meas measured value

5

zone

model modeled value

surf property/quantity for the surface layer

\section{ACKNOWLEDGEMENTS}

This work was supported by the U.S. Department of Energy under Contract No. DE-AC36-08-GO28308 with the National Renewable Energy Laboratory. We would like to thank Bruce Wilcox and Rick

Chitwood for helping with setup at the California house and Eric Martin and David Hoak for helping with the Florida house. We also want to thank Greg Barker for help with programming the data-acquisition system and Ed Hancock for his invaluable support with equipment setup.

\section{REFERENCES}

[1] Woods, J., J. Winkler, D. Christensen, Moisture modeling: Effective moisture penetration depth versus effective capacitance, in Thermal Performance of the Exterior Envelopes of Whole Buildings XII International Conference. 2013: Clearwater, FL.

[2] Rudd, A. and H. Henderson, Monitored indoor moisture and temperature conditions in humid-climate US residences, ASHRAE Transactions. 113(1) (2007) 435-49.

[3] Henderson, H., D. Shirey, C.K. Rice, Can conventional cooling equipment meet dehumidification needs for houses in humid climates?, in 2008 ACEEE Summer Study on Energy Efficiency in Buildings. 2008: Pacific Grove, CA.

[4] Henderson, H., D. Parker, Y. Huang. Improving DOE-2's RESYS routine: User defined functions to provide more accurate part load energy use and humidity predictions, in 2000 ACEEE Summer Study on Energy Efficiency in Buildings. Pacific Grove, CA, 2000.

[5] EPA, Indoor Assessment Tool (IHAT) reference manual. US Environmental Protection Agency, 2001.

[6] Fang, X., J. Winkler, D. Christensen, Using EnergyPlus to perform dehumidification analysis on Building America homes, HVAC\&R Res. 17(3) (2011) 268-83. 
[7] Kuenzel, H.M., A. Karagiozis, A. Holm, WUFI ORNL/IBP A Hygrothermal Design Tool for Architects and Engineers. 2001, Chapter ASTM Manual 40 in Moisture Analysis of Buildings.

[8] Combined Heat and Moisture Transfer (HAMT) Model, EnergyPlus Engineering Reference. 2013, US Department of Energy. p. 47-52.

[9] Kerestecioglu, A., M. Swami, A. Kamel, Theoretical and computational investigation of simultaneous heat and moisture transfer in buildings: "Effective penetration depth" theory, ASHRAE Transactions. 96(1) (1990) 447-54.

[10] Cunningham, M.J., Effective penetration depth and effective resistance in moisture transfer, Build. Environ. 27(3) (1992) 379-86.

[11] Cunningham, M.J., The moisture performance of framed structures - a mathematical model, Build. Environ. 23(2) (1988) 123-35.

[12] Woods, J., J. Winkler, D. Christensen, Evaluation of the effective moisture penetration depth (EMPD) model for estimating moisture buffering in buildings. NREL/TP-5500$57441,2013$.

[13] Janssen, H. and S. Roels, Qualitative and quantitative assessment of interior moisture buffering by enclosures, Energ. Buildings. 41(4) (2009) 382-94.

[14] Abadie, M.O. and K.C. Mendonca, Moisture performance of building materials: From material characterization to building simulation using the Moisture Buffer Value concept, Build. Environ. 44(2) (2009) 388-401.

[15] Rode, C. and K. Grau, Moisture buffering and its consequence in whole building hygrothermal modeling, J. Build. Phys. 31(4) (2008) 333-60.

[16] Yang, X., P. Fazio, H. Ge, J. Rao, Evaluation of moisture buffering capacity of interior surface materials and furniture in a full-scale experimental investigation, Build. Environ. 47((2012) 188-96.

[17] Dubois, S., F. McGregor, A. Evrard, A. Heath, F. Lebeau, An inverse modelling approach to estimate the hygric parameters of clay-based masonry during a Moisture Buffer Value test, Build. Environ. 81((2014) 192-203.

[18] Svennberg, K., L. Hedegaard, C. Rode, Moisture buffer performance of a fully furnished room, in Performance of Exterior Envelopes of Whole Buildings IX International Conference. 2004, ASHRAE.

[19] Vereecken, E., S. Roels, H. Janssen, In situ determination of the moisture buffer potential of room enclosures, J. Build. Phys. 34(3) (2011) 223-46.

[20] Vieira, R. and J. Sherwin, Flexible Residential Test Facility Instrumentation Plan. Flordia Solar Energy Center for DOE Building America Program, 2011.

[21] Woods, J., J. Winkler, D. Christensen, E. Hancock, Using Whole-House Field Tests to Empirically Derive Moisture Buffering Model Inputs. National Renewable Energy Laboratory, NREL/TP-5500-62456, 2014.

[22] Wilcox, B., http://www.proctoreng.com/dnld/CVRHProjectWholeHouseConcept.pdf.

[23] NREL, NREL's Advanced Thermal Conversion Laboratory at the Center for Buildings and Thermal Systems: On the Cutting-Edge of HVAC and CHP Technology (Revised). National Renewable Energy Laboratory, Report No. BR-550-34928, 2005.

[24] Sherman, M.H., Tracer-gas techniques for measuring ventilation in a single zone, Build. Environ. 25(4) (1990) 365-74.

[25] ASTM, E741-11, Standard Test Method for Determining Air Change in a Single Zone by Means of a Tracer Gas Dilution. West Conshohocken, PA. ASTM International, 2011. 
[26] Walker, I.S. and D.J. Wilson, Field validation of equations for stack and wind driven infiltration calculations, International Journal of HVAC\&R Research. 4(2) (1998).

[27] Osanyintola, O.F. and C.J. Simonson, Moisture buffering capacity of hygroscopic building materials: Experimental facilities and energy impact, Energ. Buildings. 38(10) (2006) 1270-82.

[28] Wilson, E., C. Engebrecht-Metzger, S. Horowitz, R. Hendron, 2014 Building America House Simulation Protocols. NREL/TP-5500-60988, 2014.

[29] Henderson, H. and J. Sand, An hourly building simulation tool to evaluate hybrid desiccant system configuration options, ASHRAE Transactions. 109(2) (2003) KC-03-51 . 